Rev. Fac. Med. vet. Zootec. Univ. S. Paulo, $13(2): 327-22,1976$.

\title{
DESALEITAMENTO PRECOCE DE BEZERROS II. RAÇOES INICIAIS COM E SEM FENO INCORPORADO
}

\section{RFMV-A/23}

IUccr, C. DE S. Desaleitamento precoce de bezerros. II. Racös iniciais com e sem feno incorporado. Kev. Fac. Med. vet. Zcotec, Linis. S. Paulo, 13(2):327-32, 1976.

Restmo: Trinta e seis bezerros machos Holandeses, puros por cruzamento, foram utilizados em um delineamento de blocos ao acaso, sendo os tratamentos dispostos em um arranjo fatorial 2x3, compreendendo jeno presente ou ausentc na raçōo inicial, com 3 niveis de proteina digestivel: $12 \%, 15 \%$ c $18 \%$. O periodo cxperimental abrangeu do $14 .^{\circ}$ an $91 .^{\circ}$ dia de vida. fazendo-se o desaleitamentto aos 56 dias. Os desempenhos dos bezerros em ganhos de peso foram semelhantes nas raçóes iniciais com e sem feno, independentes do nivel prático utilizado. Concluiu-se que dar jeno como porçio integrante da raçäo inicial é uma forma de incrementar o consumo total de feno, com prejuizo do consumo deste volumoso fornecido à rontade. $\mathrm{cm}$ scparado.

UNITERros: Bezerros": Desaleitamento precoce*: Raçōes iniciais*.

\section{INTRODUÇÃO}

No Estado de São Paulo é comum a venda de bezerros machos a preços irrisórios, para frigoríficos, logo após ou durante a ingestão do colostro. Sendo animais de grande potencial para ganhar peso, desde que alimentados corretamen. te, o aproveitamento dos mesmos para produção de carne teria significado econômico elevado para a pecuária nacional.

O maior empecilho à criaçāo ciesses animais reside nos gastos em leite, na fase de pré-ruminação. O presente estudo procura trazer algum subsídio nos sistemas de desaleitamento precoce com raçōes iniciais, tendo como objetivo observar os efeitos de administrar ou não feno juntamente com a raçāo inicial, tanto no crescimento ponderal como no consumo de alimentos. Neste assunto, a literatura consultada mostrou-se pobre e bastante controvertida.

DOLGE e outros 13 estabeleceram a proporção de $17 \%$ de feno de alfafa, como ideal para incorporação em rações iniciais.

WHITAKER e outros 15 compararam raçōes iniciais sem feno, com $16 \%$ e com $32 \%$ de feno incorporado, colocando feno de alfafa à disposição de todos os be

\footnotetext{
- Professor Livre-Docente Departamento de Produçro Animal da Faculdade de Mediclna Veterinária c Zooteculca da USP.
} 
zerros. Não ocorerram diferenças entre ganhos de peso, consumo das raçōes iniciais e consumo de feno entre os dife. rentes tratamentos.

BELL 1 forneceu para um lote de bezerros, mistura de 2 partes de ração inicial e 1 parte de fenu picado. Um segundo lote recebeu os mesmos alimentos em cochos separados. Os resultados em ganhos de peso foram estatisticamente semelhantes.

NOLLER, DICKSON e HILL 10 estudaram a administraçāo de feno à vontade ou incluido na raçāo inicial. Os ganhos em peso foram semelhantes. O consumo da ração inicial com feno foi significativamente maior que o das rações iniciais sem feno. No entanto, a ingestão de concentrados foi menor na ração inicial contendo feno.

WALDERN e NELSON 11 forneceram ração inicial mais feno de alfafa à vontade ou ração inicial com $20 \%$ de feno incorporado; nāo ofertando o feno isoladamente. Os ganhos de peso, consumos de raçōes iniciais e conversões em ganhos não diferiram estatisticamente.

MACLEOD, BURNSIDE e GRIEVE 18 administraram rações iniciais contando ou não $20 \%$ de feno; todos os animais além disso receberam o feno isoladamente, à vontade. A inclusāo de feno à ração inicial resultou em maior consumo da mistura, mas em menor ingestão de concentrados. Outro fato foi que a inclusão de feno na ração inicial não diminiu o consumo do feno fornecido isoladamente. A velocidade de crescimento e a eficiência alimentar foram considerados semelhantes e a maior ingestão da ração inicial com feno foi explicada pela sua concentração energética inferior.

CHURCH 2 relatou que só uns poucos experimentos de alimentação animal procuraram estudar a administração de feno na ração inicial ou separadamente.
Ncs poucos dados disponiveis a proporção de feno nas misturas variou de 20 a $33 \%$ e os ganhos de peso de bezerros não foram afetados adversamente.

No tocante aos estudos sobre teores de fibra nas rações iniciais, WING 16 trabalhou com niveis de $6 \%$ e $13,9 \%$ com resultados semelhantes em ganhos de peso, consumo de concentrados e feno.

GARDNER 4, com niveis de 8,5\% e $11,6 \%$, encontrou resultados de maior consumo e maiores ganhos de peso com a ração mais fibrosa.

MILLER, MARTIN e FOWLER 9 apresentaram resultados de maiores consumos de ração e maiores ganhos de peso com rações iniciais mais ricas em fibra bruta.

LUCCI 6 usou rações iniciais com $3,8 \%, 6,7 \%$ e $9,3 \%$ de fibra bruta; com ganhos de peso semelhantes e maior consumo de raçăo inicial mais fibrosa.

JAHN, CHANDLER e POLAN : compararam rações com niveis crescentes de $5 \%$ até $60 \%$ de palha. As ingestões aumentaram com os níveis maiores de palha, até o limite de $32 \%$.

STOBO, ROY e GASTON ${ }^{13}$ determinaram que dietas ricas em concentrados provocam $\mathrm{pH}$ mais baixo no interior do rúmen, e dietas mais ricas em volumosos, como o feno, pH mais elevado. Estes AA sugerem que bezerros submetidos a dietas com altas proporções de concen. trados tem seu metabolismo energético baseado no aproveitamento de glucose, ao passo que os submetidos a dietas com altas proporçōes de feno, aproveitam o acetato como fonte de energia, em quantidades consideráveis.

ROY 12 afirma que nas proporções superiores a $3: 1$ de concentrado/feno, em uma ração, as bactérias ligadas a digestāo do feno nāo conseguem se instalar dentro do rúmen. 


\section{MATERIAL E MÉTODOS}

Foram usados 36 bezerros machos holandeses, puros por cruzamento, em um delineamento de blocos ao acaso, segundo esquema de PIMENTEL GO. MES 11, conforme explicado em trabalho anterior (LUCCI 7). O estudo foi conduzido no Centro de Zootecnia e Indús. trias Pecuárias "Fernando Costa", em Pirassununga, S. P.

Os tratamentos comparados foram 6 raçōes iniciais, compreendendo 2 níveis de $\mathrm{N}$ D T. correspondentes a presença ou essência de feno incorporado à ração: A: sem feno incorporado e $\mathbf{B}$ : com $25 \%$ de feno incorporado, cada uma com 3 niveis P. D. e $12 \%, 15 \%$ e 18\%. A composição das rações iniciais foi fornecida em trabalho anterior, tirado da mesma série de observaçōes (LUCCI 7).

O feno usado neste estudo foi o de alfafa (Medicago sativa), adquirido no comércio, de qualidade boa, folhoso, de coloração verde e sem materiais estranhos, com odor muito agradável. Sua administração à vontade em todos os tratamentos foi feito picando-o em partes de aproximadamente $2 \mathrm{~cm}$; para uso nas rações iniciais, a picagem foi feita em pedaços de $1 \mathrm{~cm}$ aproximadamente evitando-se a seletividade no consumo dos animais.

O periodo experimental teve início aos 14 e fim aos 91 dias de idade. Para os animais novos, foram executadas as manobras usuais com intenção de ensiná-los a comer alimentos sólidos (ROY 12). As rações iniciais eram ofertadas diariamente, sendo as sobras pesadas e desprezadas. As ingestões de todas as rações iniciais foram limitadas a um máximo de $25 \mathrm{~kg}$ por dia e por bezerro. Também o feno foi ofertado diariamente, da mesma forma que com as misturas concentradas.

Os teores estimados de fibra bruta para as diferentes rações iniciais foram:
$\mathrm{A} 1-5,8 \% ; \mathrm{A} 2-6,0 \% ; \mathrm{A} 3-6,2 \% ; \mathrm{B} 1$

- 11,6 $6^{0} ; \mathrm{B} 2$ - $11,8 \%$ e B3 - 12,0\% .

Os teores de N.D.T. foram iguais a $76,2 \%$ para as raçōes " $A$ " e 69,2\% para as raçōes " $B$ ".

Os animais foram pesados e medidos em alturas nas cernelhas e perímetros abdominais a intervalos semanais, sempre à mesma idade a partir dos 14 dias.

\section{RESULTADOS}

Os ganhos de peso dos bezerros nas raçōes iniciais A (sem feno) e B (com $25 \%$ de fenol foram respectivamente: $0,539 \mathrm{~kg}$ e $0,470 \mathrm{~kg}$, no período de 14 a 91 dias de idade. Os perímetros abdo. minais em centímetros ganhos por bezerro foram $41,4 \mathrm{~cm}$ (A) e $40,3 \mathrm{~cm}$ (B). Ambos os resultados foram estatisticamente semelhal.tes. Não houve efeitos dos niveis de P. D. estudados.

A Tabela 1 mostra consumos médios de alimentos, em quilogramas por bezerro, de rações iniciais de feno de alfafa, das quantidades de concentrados ingeridas com as raçōes iniciais e do feno total (feno isolado + feno incorporado às rações $\mathrm{B}$ ).

Os consumos das raçōes iniciais durante o transcorrer do periodo experimental podem ser observados na Figura 1. Os consumos do feno de alfafa, ofertados à vontade, podem ser vistos na Figura 2.

As proporções concentrados: feno (da ração inicial $\mathbf{B}+$ feno à vontade) foram 6,9: $1 \mathrm{em}$ "A" e 2,4: $1 \mathrm{em}$ " $B$ ".

O coeficiente de correlação entre ingestões de ração inicial " $A$ " e de feno de alfafa foi igual a $r=0,425$; e entre ingestōes de ração inicial " $B$ " e de feno de alfafa foi $r=0,389$. Ambos os coeficientes não foram considerados significativos. 
TABELA 1 - Consumo, dos 14 aos 91 dias de idade, de rações iniciais, feno de alfafa, concentrados e feno total (à vontade + incorporado).

\begin{tabular}{|c|c|c|c|c|}
\hline Tratamentos & $\begin{array}{l}\text { Ração } \\
\text { Inicial }\end{array}$ & $\begin{array}{l}\text { Feno } \\
\text { (à vontade) }\end{array}$ & Concentrados & $\begin{array}{l}\text { Feno } \\
\text { Total }\end{array}$ \\
\hline$A 1$ & 101,4 & 16,4 & 101,4 & 16,4 \\
\hline A2 & 98,8 & 10,5 & 98,8 & 10,5 \\
\hline A3 & 92,4 & 17,5 & 92,4 & 17,5 \\
\hline B1 & 107,8 & 7,7 & 80,8 & 34,7 \\
\hline $\mathrm{B} 2$ & 96,0 & $4, i$ & 72,0 & 28,1 \\
\hline B3 & 122,6 & 8,4 & 92,0 & 39,0 \\
\hline "A" & 97,5 & 14,8 & 97,5 & 14,8 \\
\hline “B” & 108,8 & 6,7 & 81,6 & 34,0 \\
\hline “1" & 104,6 & 12,1 & 91,1 & 25,5 \\
\hline "2" & 97,4 & 7,3 & 85,4 & 19,3 \\
\hline “3” & 107,5 & 12,9 & 92,4 & 28,1 \\
\hline Análises & $\mathrm{B} 3>\mathrm{A} 3\left({ }^{*}\right)$ & $A \leadsto B(*)$ & $\Lambda>B(*)$ & $\mathbf{B}>\mathbf{A}(*)$ \\
\hline
\end{tabular}

A ingestão de matéria seca proveniente dos alimentos: leite, rações iniciais e feno de alfafa mostraram os seguintes resultados, em quilogramas por bezerro, considerados estatisticamente semelhantes:

$$
\begin{array}{rl}
\mathrm{A} 1=115,6 & \mathrm{~A} 2=108,0 \\
\mathbf{B} 1=112,8 & \mathrm{~B} 2=99,8 \\
\text { "1" } 1 "=114.2 & =103,9 \\
& \mathrm{~A}=111,2 \\
\mathrm{~A} 3=110,2 & \mathrm{~B}=113,5 \\
\mathrm{~B} 3=128,0 & \mathrm{M}=112,4
\end{array}
$$

As conversões de M.S. em ganhos de peso, apresentaram os seguintes resultados:

$$
\begin{array}{rl}
\text { A1 }=2,798 & \text { A2 }=2,620 \\
\text { B1 }=3,050 & \text { B2 }=3,305 \\
\text { "1" }=2,924 & \text { "2" }=2,962 \\
& \\
\text { A3 }=2,786 & \text { A }=2,735 \\
\text { B3 }=3,235 & \mathrm{~B}=3,197 \\
\text { "3" }=3,010 & \mathrm{M}=2,966
\end{array}
$$

A diferença entre " $A$ " e " $B$ " foi con siderada significativa. Não ocorreram diferenças entre niveis de P.D.

\section{DISCUSSĀO}

Os ganhos de peso com rações iniciais contendo ou não feno incorporado foram semelhantes. Isto concordou com os resultados dos trabalhos de WHITA. KER e outros 15 BELL 1, NOLLER, DICKSONN e HILL 10, WALDEMAR e NELSON 1.1 e MACLEOD, BURNSIDE e GRIEVE 8. Já DOLG e outros 13 apresentaram ganhos de peso mais elevados obtidos com bezerros recebendo raçōes iniciais com $15 \%$ a $20^{\circ}$ de feno incluído.

Os dados referentes ao consumo de alimentos sólidos por bezerros muito novos variam bastante, inclusive como caracteristica individual dos animais, conforme já resultaram WHITAKER e cutros 10. No entanto, é notável o fato de que, após os 56 dias, quando privados 
de leite, os bezerros passaram imediatamente a ingerir maiores quantidades $d ?$ raçōes iniciais, a excessão dos bezerros recebendo B3 (Figura 1). Houve também aumento de consumo de feno, de maneira mais nítida nos tratamento " $B$ " (Figura 2).

O consumo das rações A e $\mathbf{B}$ foram estatisticamente semelhantes. No entanto, vários AA encontraram ingestōes maiores para rações iniciais com feno incluido, explicando que isto ocorreria devido à procura pelo animal. de um equilibrio no consumo de energia (MACLEOD, BURNSIDE e GRIEVE 18; WALDEMAR e NELSON 11; NOLLER, DICKSOON e HILL 10; JAHN, CHAND. LER e POLAN 15). O maior teor de fibra bruta na mistura tem provocado também consumos mais elevados, dentro do mesmo raciocínio də compensação energética (GARDNER10; MILLER, MARTIN e FOWLER 9 e LUCCI 6).

WHITAKER e outros 15, concordando com os dados do presente trabalho, relataram consumos idênticos de raçōes iniciais com e sem feno incluido. WING 16 relata consumos semelhantes de raçōes com diferentes níveis de fibra bruta.

Os consumos de feno de alfafa, fornecido à vontade, mostraram superioridade para "A" em relação a "B". Sendo limitada a capacidade do rúmen de be"zerros, seria razoável um resultado desta natureza mas MACLEOD, BURNSIDE e GRIEVE 13 e WHITAKER e outros 15 concluiram diferentemente, que o feno incluido na raçāo inicial não diminui o consumo de feno isolado.

O consumo de concentrados foi significativamente maior em " $A$ " que em "'B, fato também notado por NOLLER, DICKSON e HILL 10 e MACLEOD, BURNSIDE e GRIEVE 18, comparando rações iniciais contendo ou não feno. No consumo total de feno (presente nas rações iniciais "B" mais feno à vontade), inversamente, o tratamento " $\mathrm{B}$ " foi 0 favorecido.
As proporçōes entre concentrados : feno total favorecem os tratamentos " $A$ ", ultrapassando o nivel critico $3: 1$ acima do qual as bactérias ligadas a digestão do feno desaparecem (ROY12). Tomando como base os resultados apresentandos por STOBO, ROY e GASTON ${ }^{13}$, o valor $\mathrm{pH}$ no interior do rúmen dos animais do tratamento " $\mathrm{A}$ " foi provavelmente meror, e o metabolismo, mais orientado para a utilizaçāo de glucose como fonte de energia, enquanto em "B" o acetato deve ter sido um componente energético mais importante. Se estas fatos realmente ocorreram, explicam o melhor aproveitamento das raçêes " $A$ " em relação às raçōes " $B$ ", refletidas nos melhores índices de conversão em ganho de peso, ocorridas em "A".

\section{CONCLUSOัES}

Nas condiçōes do experimento, é possivel emitir as seguintes conclusōes:

1.a) Os desempenhos dos bezerros em ganhos de peso foram semelhantes para raçōes iniciais com e sem feno incluído. Não surgiram efeitos dos diferentes niveis protéicos das rações iniciais.

2.a) Os consumos das rações iniciais com feno incluido e sem feno incluído foram semelhantes.

3.a) O consumo do feno de alfafa fornecido à vontade, foi mais elevado por parte dos bezerros que recebiam rações iniciais sem feno incluído.

4.a) O consumo de concentrados foi mais elevado nas rações iniciais sem feno incluido, ao conttrário, o consumo de feno total (isolado + incorporado às rações) foi maior para o caso das rações com feno incluído.

5.a) Dar feno na ração inicial além de à vontade, é uma maneira de incrementar o consumo total de feno, com prejuizo do consumo do feno fornecido à vontade. 
Luecr, C. DE S. Early weaning of calves. II. Calf starters with and without hay. Rev. Fuc. Med. vet. Zootec. Unlv. S. Paulo, 1:3(2):327-32, 1976.

Summary: Thirty six Holstein male calves were used in a randonmized block design, with a $2 x 3$ factorial arrangement for treatments concerning calf startes with $25 \%$ included hay and calf startes without hay. cach onc wilh three levels of digestible protein $112 \%, 15 \%$ and $18 \%)$. The experimental period was from 14 to 91 days old, with weaning age at 56 days. The performance of calves was similar in ueight gains at all treatments. It was concluded that to give hay Included in calf starters increases total hay consumption but declines the intake of ad libitum hay.

UNITERMS: Calves"; Restricted milk weanin/system*; Calf starters".

\section{REFERENCIAS BIBLIOGRAFICAS}

1 - BELL. J. M. Raising dairy calves without whole milk. Canad. J. Anim. Sci., $38(2): 103-8,1958$.

2 - CHURCH. D. C. Digestive physiology and nutrition of ruminants. Oregon. O.S. U. Book Stores Inc.. 1972. v. 3. p. $93-131$.

3 - DOLGE, K. L.; EATON. H. D.: MOCHRIE, R. D.: AVAMPATO. J. E.: ELI,IOT. F.I. Effect of initinl level and rate of increase of artificlally dehyorated alfafa in complete rations on growth carotene intaye of Holstein dairy calves. J. Dairy Sci., $36(3): 235-45,1953$.

4 - GARDNER, R. W. Acceptability and nutritional response comparisons between calf starters. $J$. Dairy Sci. SO(5) :729-34. 1967.

5 - JAHN, E.: CHANDLER. P. T.: POLAN. C. E. Effects of fiber and ration of starch to sugar on performance of rumlnating calves. J. Dairy Sci., 53 (4) :466-74, 1970 .

6 - LUCCI. C. de S. Estudo sobre o efelto de diferentes nivels de fibra bruta em raçóes de desmama precoce de bezerros de raças lelteiras. Bol. Ind. Anim., 29(1):67-149, 1972.

7 - LUCCI. C. de S. Desaleltamento precoce de bezerros. I. Niveis de proteina enerğla nas raçōes iniciais. Rcv. Fac. Mcd. vet. Zootec. Univ. S. Paulo, 13 (2): $\quad, 1976$.

8 - MACLEOD. G. K.: BURNSIDE. E. B.; GRIEVE, D. G. Growth of Holstein and Jersey calves in response to four feeding programs in a breed by raton interaction study. J. Dairy Sci., $53(9): 1270-74.1972$
9 - MILLER, W. J.: MARTIN, Y.G.: FOWLER. P.R. Effects of nddition of flber to simplified and to complex starters fed to young dairy calves. J. Dairy Sci., S2(5):672-6, 1969.

10 - NOLLER, C. H.: DICKSON, I. A.; HILL, D. L. Valve of hay and rumen inoculation in an early wenning system for dairy calves. J. Dairy Sci., 45: 197-201. 1962.

11 - PIMENTEL GOMES. F. Curso de estatística experimental. 3 ed. Piracicaba. ESALQ. 1972.

12 - ROY, J. H. B. The call, London, Farmer \& Stockbreeder. 1970. $2 \mathrm{v}$.

13 - STOBO. I. J. F.: ROY. J. H. B.: CASTON, H. J. Rumen development in the calf. II. The effect of diets containing different proportions of concentrate to hay on digestive efficiency. Brit. J. Nutr., 20:188-215, 1966

14 - WALDERN, D. E. \& NELSON, D. K. Complete starters rutlons for replacement dairy helfers. J. Dairy Sci., 51(6): 972. 1968.

15 - WHITAKER, R. T.: MILLER, W. J.: CARMON, J. L.: DALTON, H. L. Influence of level and source of crude ftber in calf starters on weight and fecd consumption. J. Dairy Sci., $40(8)$ : 887-92, 1957.

16 - WING. J. M. Effect of a simple highflber feed on dalry calves. J. Dairy Sci. 42(11):1877-9. 1959.

Recebido para publicação em 27-7-76 Aprovado para publicaçåo em 13-9-76 